\title{
Students' Learning Experiences With LMS Tes Teach In Flipped-Class Instruction
}

\author{
Zamzami Zainuddin $^{1}$, Hardika Dwi Hermawan ${ }^{1}$, Febritesna Nuraini ${ }^{2}$, Santo Mugi Prayitno ${ }^{3}$ \\ ${ }^{1}$ Information and Technology Studies The University of Hong Kong, ${ }^{2}$ Early Childhood Education Departement, Ahmad \\ Dahlan University, ${ }^{3}$ Elementary School 2 Bangunrejo Yogyakarta \\ E-mail: u3542317@connect.hku.hk
}

\begin{abstract}
The purpose of this study was to identify the impact of implementing a Learning Management System (LMS) 'TES Teach' on students' learning experiences in a computer-assisted language learning (CALL) course with flipped-class instruction. For the data collection procedure, an individual interview with ten undergraduate students from an Indonesian college was conducted to demonstrate the potential impacts of the LMS in students' meaningful learning activities. The observation of students' learning activities on the LMS was also recorded to support the interview data. The LMS was adopted to distribute and receive information, thus, the students were able to monitor learning activities, learn the contents before coming to class, evaluate learning process, and interact with others outside of class hours. The finding of this study suggests that the LMS TES Teach is recommended to be performed in teaching CALL for higher education in Indonesia. It offers students' occasion to practice and enhances their listening, writing, reading and vocabulary skills in and out-of-class times. It also prepares students to get ready for classroom activities in term of conversations and speaking skills. The further use of the LMSs should become often-visited sites by students for learning activities and replaced other non-educational favorite websites.
\end{abstract}

Keywords: Flipped Classroom, Technology-enhanced learning, LMS, EFL

\section{INTRODUCTION}

English is taught and used as a foreign language (EFL) in Indonesia. Although English is considered as a foreign language, mastering this language is required for Indonesians to improve their job and career prospects in the $21 \mathrm{st}$ century [1]. In improving the quality of English language teaching, many studies have been reported concerning the utilization of technological devices. For example, teaching English is a process where the students require to learn step-by-step to follow the process and need to practice a lot [2]. They suggested using technology devices in teaching English, where the students can practice on their own everywhere, not only in the classroom but also at home. At the same time, most students also have been familiar with different technology tools and most of them allocate most of their daily hours using some sort of technological devices. The use of technological tools enables students to interact with peers or instructor and learn contents everywhere, not only in the class but also outside the class hours [3]. Using technology tools bring a number of benefits for students and instructors in learning English and countless of free lessons have been provided on many websites [4]. Incorporating computer technology in learning languages, so-called Computer-Assisted Language Learning (CALL), is aimed at helping transforming the instruction from being a traditional to technology-based learning environment, and from teacher-cantered to learner centered approach, and at the same time to promote collaborative learning, self-directed learning and a ubiquitous learning environment [5].

The implementation of the teachercentered approach in today's digital age is irrelevant since many free contents provided on the internet and enable students to access them at any time [6]. It is believed that the conventional classroom activities such as lectures and 
homework can be transferred online and the students can work everywhere according to their pace [3]. The flipped classroom is one of those variants implemented in current teaching and learning practices by adopting technology tools such as video lectures and Learning Management System (LMS).

The flipped classroom is often defined as an instructional strategy and a part of blended learning instruction, where the students attempt to understand and comprehend the instructional contents before attending class by watching video-recorded lectures. In-class activities are subsequently more focused on promoting students' higher-order thinking skills or knowledge construction, such as small group discussion, dialog, presentation, and take-andgive conversation or the so-called Socratic questioning process [7]. Flipped-class instruction facilitates content retrieval autonomously before attending class, enables peer communication and facilitates an asynchronous channel for watching video lectures while replacing repetitive conventional classroom lectures. The flipped classroom is also defined as synonymous with using the videos and replacing the conventional classroom lectures. In order to preserve the time designing or recording the video lessons, the lecturers may use an alternatives way by adopting a short video lecture from several free websites such as Khan Academy, TED-Ed, BBC News, or YouTube [8].

In this study, the instructor adopted preclass video lessons from YouTube channel with a short duration and attractive contents. In designing or selecting the video lesson, the content of a video should be attractive and its duration is not too long [9]. Other researchers also suggested that the video lesson should be designed attractively in order to make students comfortable and interested in watching, short and informal videos will also make students be more engaging [10]. In this paper, the researcher used attractive video lessons adopted from YouTube and posted on the LMS TES Teach with the aim of enhancing students' innovative learning activities in the computer assisted language learning course (CALL).

Formerly known as BlendSpace, TES Teach is a Learning Management System (LMS) particularly designed for educational purposes and focused on blended learning, project-based learning, and flipped classroom activities. With this LMS, teachers or instructors can create free classroom and share various contents for students' learning outside the class. The following Figure 1 shows the home page of TES Teach where teacher and students can register as users.

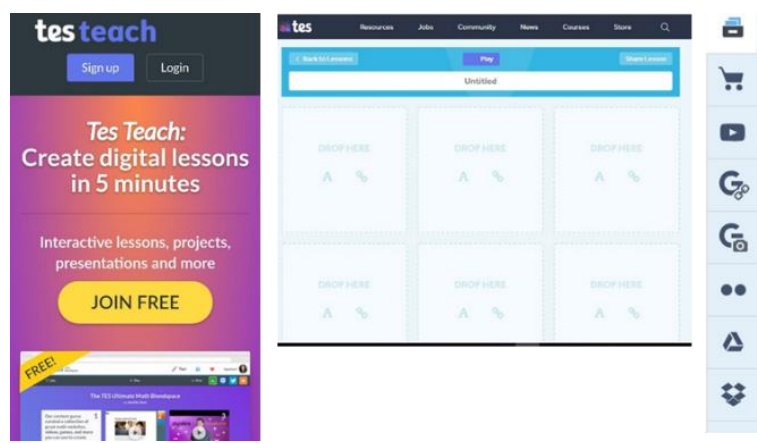

Figure 1. Homepage of TES Teach, columns for uploading contents of learning and direct links to various sources

To begin creating the class and lesson, the teachers/ instructors should register as a user at the homepage. By clicking "JOIN FREE", the users will be guided to two options whether teacher or students' users. As a teacher, she/ he must register and click "I'm a TEACHER". Then, the user can fill the form including name, e-mail, and password. Besides, the users may also Log in directly with Google or Facebook account. The users then continue creating the class, choose a grade level and the name of the class. After creating the class and obtaining the class code, the user may create new lessons by clicking "Lessons" or "New Lesson". Then, it will be directed to space which has nine columns (add a row if needed) where the content will be put or uploaded. In the column, the users can upload the texts, quizzes or video. They can also write the instruction in the column of what students should do with the video and what activities students should prepare for the next 
class meeting. The content of learning can be dragged to the column or search it in the top right corner. There are numerous searches provided such as YouTube search, Google search/ image, Flickr search, Insert from Dropbox and Insert from Drive.

\section{METHOD}

This study was administered to review the impacts of employing the LMS TES Teach to enhance students' autonomous learning, critical thinking, and peer-interaction skills in the CALL course with a flipped-class model. It particularly observed the interactions and engagement among students and between the students and the LMS outside of the class. A qualitative approach was employed in this study and the data was gathered from individual interview and observation of students' activities on the LMS. This individual interview involved semistructured questions with audiotape and transcribe it [11]. 10 EFL students from a university in Indonesia were selected as a sample of interviewees at the end of academic semester. They had worked and experienced with the LMS TES Teach prior to this course. In order to keep students' privacy, all ten students in the interview were reported anonymously and arranged alphabetically. The interviews ranged in length from 30-40 minutes and questions were recorded verbatim. The interview analysis used a stepwise design or a step-by-step guide proposed by Patton. The process consisted of three steps: (1) Assemble the raw case; the interviews were transcribed by the researcher to get the print version of the interview, (2) Construct the case record; the raw data of students' motivation was classified in themes and edited by the researcher, (3) Report a final case; the result of interview discussion was reported descriptively according to their themes [12]. In order to triangulate the data and to improve high credibility and objectivity of this qualitative study, we invited different colleagues in the same field to serve as evaluators, investigators, or raters. In this study, three raters were asked to put the transcripts in rank order from the most perfectionist (1) to the least perfectionist (8) [13]. From the rating questions, we found that two evaluators put the transcripts in rank 2 and the other in rank 3 . This can be implied that the analysis of transcription data was objective since the researchers used three different independent investigators in the analysis process or the so-called investigator triangulation.

In CALL flipped learning class, the instructor conducted a face-to-face meeting in the classroom once a week and the duration was 1 hour and 40 minutes (100 minutes). Six steps had been implemented by the instructor in flipping the course. First, the instructor shared one video every week on the LMS and the video was adopted from YouTube channel. Overall, six videos had been distributed by the instructor over a six-meeting period. The duration of videos was varied, the shorter was 6:24 minutes and the longest was 16:16 minutes. The first video titled "Computer-assisted language learning (CALL) today - a critique", second "Blending technology and classroom learning", third "Every kid needs a champion", fourth, "Digital natives vs. digital immigrants", fifth "How to give the BEST speech or presentation in English", and sixth "6 Tips to Increase Your Confidence". Besides, the instructor also shared other supporting materials such as PDF articles and websites to support students' learning outside of the class.

Second, students watched a video and read supporting materials before coming to class. Third, students conducted an online discussion by posting questions and comment regarding the video contents. The use of TES Teach is very relevant for enhancing students' collaboration since it is has a special space for collaborative tasks among students as well as with the instructor. It provides a synchronous chat and asynchronous discussion board. The students in this study were able to post their comments and ask questions to the group online. The following Figure 2 shows several YouTube videos posted on the LMS. 


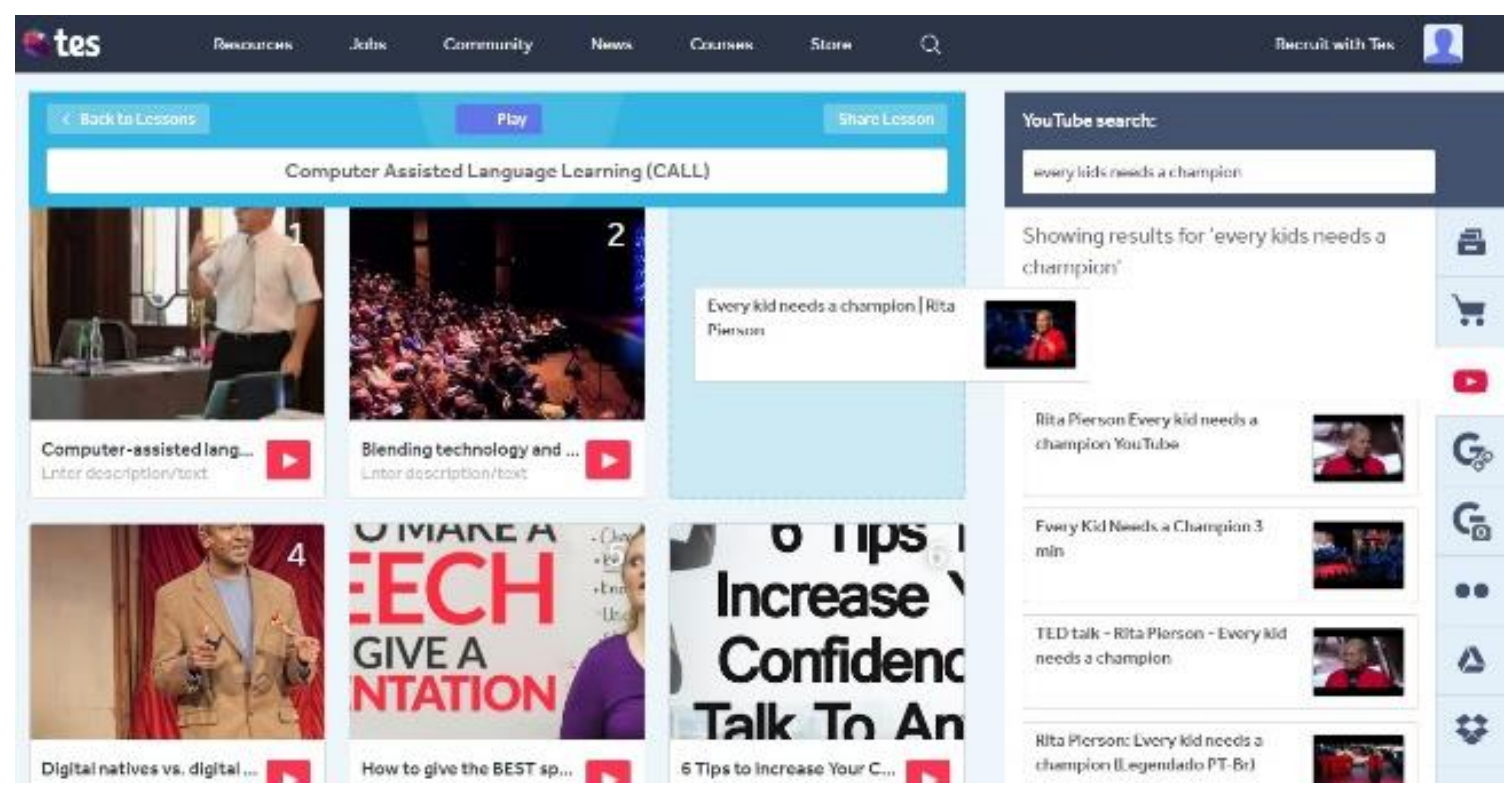

Figure 2. YouTube videos had been dragged to the LMS TES Teach

Fourth, when in-class, a 40-minute was allocated for listening exercise. Fifth, 45-minute was allocated for conversation activity, and sixth, 15-minute was allocated for interactive feedback and a small quiz session. The feedback was given by instructor or students (peerevaluation). The following Figure 3 summarizes the steps of implementing the instruction.

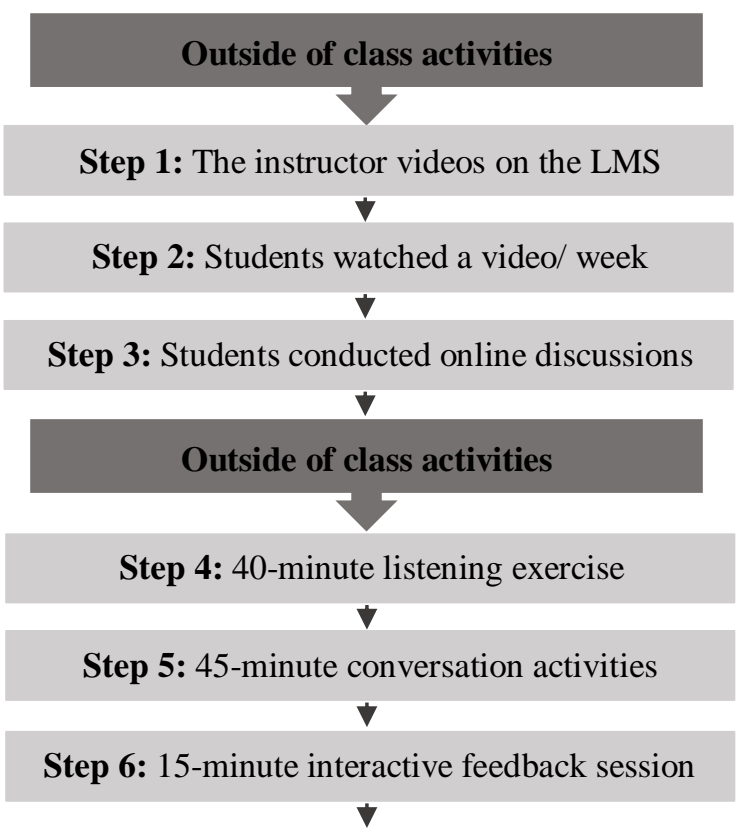

Figure 3. The steps of implementing CALL/ EFL flipped-class instruction

\section{FINDINGS}

The findings of this study reveal that almost all students were positive about the use of the LMS TES Teach in CALL course. In other words, the majority of the learners perceived this LMS positively. There were four main positive themes that emerged during personal interviews. The first major positive theme was "Information distribution and messaging". Most students acknowledged the information distribution as the primary function of the LMS. One student expressed the LMS as a beneficial device to share and acquire new information, and another mentioned that this LMS was useful in making information available immediately and saving energy and time. By using this LMS, class materials can be shared online and students can access them conveniently. At the same time, the instructor may save their times in preparing the printing materials or a hard copy for students' inclass activities.

The type of information distribution in this study could be an announcement or message, learning materials, or homework. Students or instructor were able to post announcements to the LMS group, distribute some learning 
materials for group sharing, and establish a discussion forum. See the example of announcement distribution in the following Figure 4.

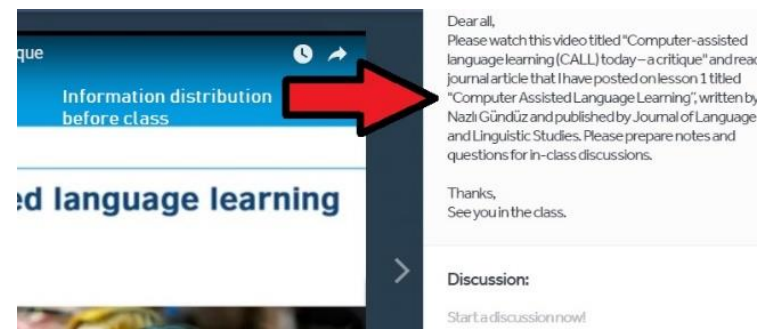

Figure 4. Announcement distribution on the LMS

These are some statements from the students and indicate that the usage of TES Teach LMS brought benefits in term of information distribution and messaging. A typical response was: "TES Teach allows me to now new announcement form my lecturer, the lecturer shares announcement by a single posting and everyone can assess it immediately, she [lecturer] doesn't need to call or text students one-by-one for the announcement." Besides, two students also commented on the helpfulness of having the LMS for checking upcoming activities and knowledge exchange, stating that "I can access this site every day to update new information from my lecturer or classmates. This site also allows me to check upcoming class activities, and I also can share papers and videos to others" and "I use this LMS primarily as a source of information for my learning and I can exchange information with my friends. Also, important information...or problem can be directly shared and discussed here."

Features provided on the LMS TES Teach allow students to manage a discussion forum, collect and share resources, receive and share announcement, upload the video lessons, add the assignment, and create flipped lessons. This site enables instructors to design lesson plans easily, the site also provides diversity of resources such asYouTube Videos, Google Search Results, Google Images, and Flcker images. For students who could not attend the class, they also enabled to contact the instructor immediately on the
LMS. The instructor also could inform students whether she would be in the class on time or late, or the class was reschedule.

The LMS TES Teach element is designed to promote students' monitor their learning activities especially during outside of-classhours. Six interviewees acknowledged that they accessed the LMS regularly before attending the class to check update information about the topic discussion from peers and instructor, for instance, student A mentioned: "I log in into the LMS to check if there is new information or posting there. Yeah...I see other comments, questions, and new materials, this makes me login the LMS more often. This site made me able to control the progress of my learning activities outside the class and I could prepare for the next class activities of course." This statement was strengthened by student F: I always access this Web to check any update information such as new videos or students' comments. I received many replies on my questions and comments. Therefore, I often access them every day and I was able to read new information, respond comments, and ask questions to my friends and instructor. Through this website I would never miss any single update information." (Student F)

Two students mentioned that by monitoring information on the LMS, they did not need to ask friends about new update information related to the next class meeting, student A stated: "I can update the information independently at any time, in the previous class, I always contact my friends to ask about any assignment or update information about the next classs meeting, but I don't need in this class, all learning information is updated." Student G also declared that the use of LMS Test BlenSpace was very helpful to control the new information independently outside of class hours: "Although we are not in the class, we can still follow any update information about learning activities online outside the class".

Some also described that the TES Teach is being convenient, a good design and easy to use. For example, one student described the TES Teach enabled students access the course 
material when they missed the class: "When I miss the class, I would not miss the lesson because I could access it on the LMS conveniently from my home, all materials are posted on the LMS and I could learn it by myself............ and I think this site is simple to use and the content of the video is also interesting, everyone can access it easily, yes, great."

However, only two students noticed that they rarely login to the LMS because they did not find any interesting topic posted by the instructor and there were many questions posted by students. In this case, student $\mathrm{J}$ acknowledged: "If there is any interesting topic to me, I will often log in and check the TES Teach, if not, I am very lazy to access it". This declaration was strengthened by student I: "....... if the video and topic discussion is interesting to me, I will often study more about it and posted questions actively and respond comments". These two statements indicated that the attractiveness and interesting of video lectures or materials on the TES Teach played a very significant role in establishing students' motivation and engagement to monitor the LMS regularly.

"Pre-class learning activities" is the next major positive theme. The flipped classroom approach has significantly enhanced students' autonomous learning skill by mastering the content at home before attending class or becoming well-prepared for classroom activities. By watching a video lesson and reading a some printed material, students' became more confident in-class activities. Students acknowledged that the use of LMS TES Teach helped them access the content anytime and wherever. Students also explained that by mastering the content before attending the class allowed them to come up with a critical thinking or immediate critical questions during the class discussion. For example, student $\mathrm{E}$ and $\mathrm{C}$ in the interview reported: "I can prepare the subject outside the class by watching the video lesson posted on the LMS TES Teach, and this activity makes me more confident for classroom activities and discussions" and "By watching a YouTube video outside the class, I could prepare what would be discussed and asked in the classroom. I also could watch the video according to my preferred time, before sleeping on my bed or when waking up in the morning.......also, I could repeat watching the video several times when I did not understand."

By providing lectures online, the students have a chance to learn and understand the content at their own pace. Once a student did not understand a concept they learned, they could repeat learning it according to their needs. By providing the content on the LMS before the class hours, some students who needed more times to master the content would not leave behind. On the other hand, for those who had understood the concept, they could move on. This means all students did not learn the contents in the same area and at the same time outside the class hours.

Two students also reported that accessing the LMS became their learning habit every night before going to the bed and they did not realize that they spent every night accessing the LMS online course like other social media such as Facebook and Twitter. In this case, the LMS TES Learn has successfully blended students' learning activities between face-to-face meeting in the class and online learning outside the class. They also asserted that watching a video lesson outside the class gave them ample opportunity to practice English listening and writing skill, as well as note-taking. For example, student $\mathrm{A}$ and D stated: "All video lessons posted by the instructor were in English and I could practice my English listening skill by watching those videos on the LMS" and "I was enable to practice English writing by taking a note about the video I watched, and posted a question and comments on the LMS by English".

Other also stated that effort to master the content outside of the class independently could improve their creative and critical thinking skills, particularly during group work discussion in the class. Based on this finding, it can be assumed that watching video lessons out of class allowed students to grasp a gist of the lesson before attending class and prepared for critical questions. Students could construct their own 
knowledge to understand to content. This findings can be summarized that successfully improved students' learning autonomy outside of the class through the internet activities might also successfully improve students' technological literacy, self-paced learning, and critical thinking skills.

The other main positive theme was "Students' peer interaction". The flipped learning environment allocates more times for the students to interact with peers and instructor both in and out of class hours. This finding proved that flipped classroom had established a strong social interaction among students, teach and exchange knowledge with each other. Flipped classroom has helped low ability students to learn and ask questions to high ability students. In particular, all students in the interviews recognized that the use of LMS TES Teach in the flipped learning class had constructed their active interaction with other students outside the class hours (See Figure 6). Student B verbalized a positive response and demonstrated: In this class, we could establish a good interaction with peers, not only in-class discussion but also out-of-class times......we have a chance to talk and discuss with our friends through a chat forum on the TES Teach". Student F also supported with a statement: "In other class, I rarely communicate with my friends outside of classroom, we only have a discussion with face-to-face in the class. It is very difficult if I want to contact my friends asking the lesson or homework".

Nonetheless, two students claimed that they did not talk much in class or confidently express idea verbally during the class discussion. But through the LMS, they felt confident to express idea by posting some statements or giving comments online. This LMS was also described to support students know each other personally. This showed that the LMS was recognized as a virtual environment for interacting, communicating, and understanding students' character. For example, student D and E reported: 'Through students' comments and postings on the LMS, I was able to know their characters such as their critical thinking, respectable, or helpful students" and "The TES Teach is a good application for online interaction outside the class. Through this web, I could communicate with my classmates every day after the class times. I also could know them personally especially their character by reading their comments and questions on the LMS".

This flipped learning has provided a 45minute conversation activities in the class, therefore, some students acknowledged that the class activities were very valuable for studentscentered activities such as practicing English conversation and dialogue in a small group. Respondent A noted how the flipped classroom provided a valuable time to interact with other students in practicing English writing outside the class and speaking skill in the class discussion. "The online Web TES Teach is very helpful for us, we can practice our English outside the class with peers, we can practice listening to native speakers on the video, practice writing and reading, as well as understanding new vocabularies". Students D also acknowledged the same perceptions: "...using the online Web application outside the class enabled me to practice English with my friends and improved my practice in English listening, reading and writing .... When outside the class, I could practice my writing skill by posting a comment and ask a question in English, reading some English texts, mmmm...also I could practice my English conversation confidently in a group discussion".

The resources or links posted by a student in a discussion forum also enabled students to receive new information and establish a new discussion topic. Two students agreed that new resources shared by other students on the LMS opened their minds toward other relevant issues. For example, student A acknowledged: " $M y$ friends' postings really help me improve my understanding toward the subject. Sometimes the video lessons were unclear and I got further deep information from other sources posted by my friends." (See Figure 5). This was further illustrated by student H's comments: "The instructor posted a YouTube video about the differences of digital natives and digital 
immigrants, and my friends shared other links in a discussion forum and this helped me understand the topic comprehensively."

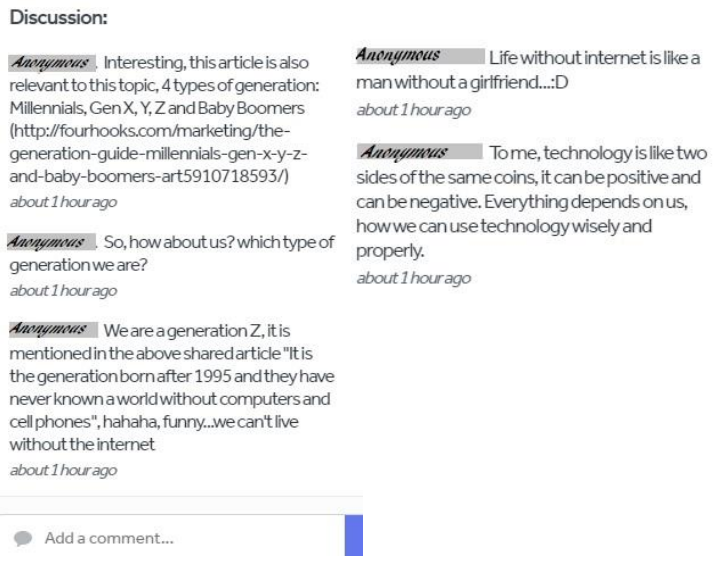

Figure 5. A screenshot of student-peer interaction on the LMS

Furthermore, students-students' interaction had also constructed students' eagerness to ask questions with peers as student $\mathrm{H}$ verbalized: I can post a question regarding the unclear video or topic, my friends will respond my question immediately. "The flipped learning class with the use of TES Teach has also increased the interaction between students and instructor. The interaction was not only established in the class activities but also outside the class hours. The instructor was able to interact with each student more personalized or more one-on-one interaction with students. This enabled the instructor to give immediate feedback for a student's progress. Also, in the classroom, the instructor was no longer stands in front of the class but she participated and involved in a students' discussion. Participants pointed their comfort and amusement of having times interacting with the instructor during the class hours and after the class through online TES Teach. Student J mentioned: "The instructor was available outside of class time, the online activities on the TES Teach made me easier to communicate with the lecturer outside the class."

The statement best expressed by Student $\mathrm{C}$ who compared her experience interacted with a instructor in a flipped classroom and traditional classroom, she stated: "This class makes me easy to talk to the lecturer in the class and it was very different with my previous class where I only sit, listen passively to my lecturer's talk and students only stay silently. The communication with the lecturer is only limited in the class, but here we can continue the discussion online on the LSM outside the class."

The last main positive theme was "Students self-evaluating learning skills". All interviewees acknowledged that the flipped class projects provided them chances to assess the performance of themselves and their colleagues. It also enabled them to know their colleagues' level in understanding the subject. Student B and I stated that they regularly reviewed if their peers did any mistakes of their postings on the LMS. Through a peer-evaluation, students could correct the mistake made by peers as well as their own mistakes. Through self-evaluation, students also declared that they could identify selfweaknesses when comparing the ability with others. "After looking at other students' comments and performance both in and out of class, I understand the level of my ability, I realize how competence I am in the class".

Besides an online assessment, students also enable to evaluate peers and themselves with face-to-face meeting in the class. Small group's discussion in the class has provided a peer-feedback on their work. Even the instructor has allocated 15-minute interactive feedback session in the end of every class meeting. This session also enabled the instructor to evaluate the whole in-class activities including the 40-minute listening exercise and 45-minute conversation activities, as well as online activities on the LMS TES Teach including watching a video lesson and online discussion. The students also verbalized that the instructor was able to deliver immediate feedback online outside the class and offline in the class hours for their improvement. For in-class evaluation, the instructor gave some comments, clarifications, suggestion, and explanations about the topics they have discussed. Student G and C mentioned: "When I posted a mistake comment on the Web, the 
instructor would correct immediately, he never say wrong to my answer, he always gives a comment and suggestion for my improvement" and ".......before finisning the class, the lecturer always asked students to give a feedback about our class activities, and finally she evaluated our activities by giving some comments, clarifications, suggestion, and explanations about the topics. "In the end of face-to face class meeting, the instructor also conclude the class with an evaluation, he gave some corrections and suggestions for students' mistakes during a group discussion.

\section{RESULTS AND DISCUSSION}

The rapid advancements in technology and the use of the learning management system (LMS) in teaching-learning activities have transformed the conventional educational instruction into a technology-based learning environment. As can be seen that many universities worldwide have utilized the LMS to enhance the quality of the teaching-learning process, provide learners with technological abilities, support learners to be more interactive, and save the time in transferring contents [14].

The usage of LMS in the flipped course makes the class material can be transferred online and enable students to master it before attending class. The use of LMS becomes a great e-learning tool in the flipped classroom where the learners could learn the content anytime and wherever outside the class time and focus on the hands-on practice in the class hours [15]. The Instructors may save their times in printing hard copy class materials and provide more times for students-peers or students-instructor interaction. Then, it has assisted student preparation contents outside of class, engagement in activities, and subsequent discussion during class activities. By employing the LMS TES Teach, students may learn independently the materials by watching videos, read PDF material and discuss online with peers at home. After preparing and learning all class materials at home, students come to class and ready to start a presentation, asking and answering the problem, or investigating solutions. In other words, the flipped learning approach can be thought of as a way of enhancing student preparedness, which in turn allows for the more efficient use of in-class time. Students are asked to use some of that prior knowledge when entering the classroom, is one of the strategies for flipped learning that is growing in popularity.

The LMS TES Teach employed in the study was designated that students were able to monitor the progress of teaching-learning activities twenty-four hours in spite at home. Students were able to read their peers' comments in other postings for comparison and selfevaluation. LMS becomes a crucial device for college students to monitor and update all information related to teaching-learning activities and obtain instant notifications from their instructor [16]. At the same time, the instructor can easily update new information or news on the LMS by a single posting.

Those who $\log$ in to the LMS regularly and learn the content before coming to class will get ready for class discussion. Students could interact with peers and instructor not only in the class activities but also after the class hours through the LMS TES Teach. By participating in the LMS, allow students to improve their perception and understanding of themselves and others. In term of intellectual capability or personal character. The LMS is used as a digital tool to change the offline activity after the class hours and students who have a limited time to interact and communicate with peers and instructor during in-class activities can interact online after the class.The LMS provided the form of students' social connection and personality, particularly outside the class time such as at home [15]. Furthermore, the instructor in this study provided immediate feedback on the student discussions. In this step, the instructor asked some critical questions to students to confirm the items that they had discussed during that period. The instructors also posted questions on the LMS after the class to evaluate the students' understanding of the concepts they have learned. Besides instructor's' evaluation, 
peer's evaluation also plays crucial roles in evaluating domain. The ability of peer evaluation was also reported in this study. One study mentioned that formative feedback from peers can help individual members fine-tune their contributions and help the group increases its overall effectiveness [10].

The activity and content provided on the LMS become a very crucial factor to support students consistently participate in the online learning activities outside the class hours. The creative and innovative activities on the LMS as well as instructor involvement plays a very significant factor to support students' participation. Nowadays, students often access various Websites for various purposes and they tend to give more attentions to some interesting Webs. The activity and content provided on the LMS become a very crucial factor to support students consistently participate in the online learning activities outside the class hours. The creative and innovative activities on the LMS as well as instructor involvement plays a very significant factor to encourage students' active participation. We are now in the true emergence of digital natives, almost all students spend most of their time in front of computers for various purposes. Thus, it is a need for further web designers/ developers to design/ develop interesting educative webs/ LMSs for students' learning activities and make those platforms interested and often accessed by students regularly. Students' engagement on the web usually comes from its interesting content and appearance, including comfortable and ease of use.

Though, the instructor may avoid to judge or assess students only on the LMS activities. We need to note that the main activities of the flipped learning actually are in-class activities where the students able to actively involved in a group discussion to construct their critical thinking and problem-solving skills. The out-ofclass activities are the only focus on students' preparation before attending class. Thus, the instructor must encourage and facilitate students to access and participate in the LMS outside the class without making a judgment (e.g., false or true) on students' postings or comments.

This study has a number of limitations that should be evaluated and continue in the future studies. The sample of the study was totally voluntary with a small size $(n=10)$. Those who were passive in-class activities tended to be silent or might not be confident enough to volunteer themselves in the interview sessions. Therefore, further study may include a big sample size and analyze different gender attitudes. We suggest that various LMSs should also be implemented in teaching CALL or EFL in Indonesian higher education. It will give a chance for students to improve their listening, writing, reading and vocabulary skills outside of the class hours. It also prepares students to get ready for in-class activities. Besides, few studies, if not none, have employed the flipped-class instruction in teaching a course related to CALLin the Indonesian context. Therefore, this study also highly recommends that future research should implement flipped classinstruction for students' learning, not only in CALL but also other subjects, by modifying the contents or online platform according to student needs or objectives of the study. This modification can be performed by adjusting the environment and culture of student learning or student learning styles. Finally, further implementation of flipped-class instruction in Indonesian higher education institutions is highly recommended in order to reform the way of teaching practice from pursuing a conventional teacher-centered to a studentcentered approach, with innovative instructions and twenty-first-century skills.

The conclusion is a summary of the results and discussion and should be written in paragraphs instead on numbering. Moreover, it can also be added the prospect of the development of research results and application prospects of further studies into the next (based on result and discussion). 


\section{CONSLUSION}

This study summarized some general advantages about the effectiveness of the LMS TES Teach in teaching-learning CALL. The LMS has potentially contributed the advancement of students' self-directed learning and peer-interaction skills. The data reported that the usage of the LMS in CALL flipped-class instruction has issued four learners' autonomy abilities, namely, receiving and distributing information, students' pre-class learning content, peer interaction, and self-evaluating learning skills. By employing the LMS TES Teach in the CALL class, the students were able to distribute and receive new information and continue online learning activities outside the class. Students were able to monitor learning activities, master the content before attending the class, establish online interaction with peers and instructor, and self-evaluate learning the process, as well as peer-evaluation or instructor-evaluation. This study recommends the further EFL instructor to implement the TES Teach and other LMSs to support students' autonomous learning skills, particularly during outside the class time. The further use of the LMSs should become oftenvisited sites by students for learning activities and replaced other non-educational favorite websites. To conclude, we highly recommend the Ministry of Research, Technology, and Higher education or policymakers in Indonesia, including instructors, students, and community members, to be actively involved in developing, supporting, and maintaining a transformed learning culture, from being a traditional to technology-based learning environment and from teacher-centered to student-centered models.

\section{REFERENCES}

[1] I. W. Dirgayasa, "Survey of English teaching and learning process in Maritme education and training in Indonesia: A case study in private MET in Indonesia," English Lang. Teach., vol. 7, no. 7, pp. 111-119, 2014.
[2] G. İlin, Ö. Kutlu, and A. Kutluay, "An Action Research: Using Videos for Teaching Grammar in an ESP Class," Procedia - Soc. Behav. Sci., vol. 70, pp. 272-281, 2013.

[3] H. Staker and M. B. Horn, "Classifying K-12 Blended Learning," Innosight Inst., 2012.

[4] J. Ahmad, "English Language Teaching (ELT) and Integration of Media Technology," Procedia - Soc. Behav. Sci., 2012.

[5] B. Derya, "English Language Teaching Students' Perceptions of Computer-Assisted Language Learning," J. Educ. Futur., no. 2, pp. 63-74, 2012.

[6] L. P. Galway, K. K. Corbett, T. K. Takaro, K. Tairyan, and E. Frank, "A novel integration of online and flipped classroom instructional models in public health higher education," $B M C$ Med. Educ., vol. 14, no. 181, pp. 1-9, 2014.

[7] Z. Zainuddin and M. Attaran, "Malaysian students' perceptions of flipped classroom: a case study," Innov. Educ. Teach. Int., 2016.

[8] Z. Zainuddin and C. J. Perera, "Exploring students' competence, autonomy and relatedness in the flipped classroom pedagogical model," J. Furth. High. Educ., 2017.

[9] D. Raths, "Nine Video Tips for a Better Flipped Classroom.," Educ. Dig., vol. 79, no. 6, pp. 1521, 2014.

[10] M. K. Kim, S. M. Kim, O. Khera, and J. Getman, "The experience of three flipped classrooms in an urban university: An exploration of design principles," Internet High. Educ., vol. 22, pp. 37-50, 2014.

[11] J. W. Creswell and T. C. Guetterman, Educational research: Planning, conducting, and evaluating quantitative and qualitative research, 6th ed. Pearson, 2018.

[12] Z. Zainuddin, "First-year college students' experiences in the EFL flipped classroom: A case study in Indonesia," Int. J. Instr., vol. 10, no. 1, 2017.

[13] T. Gregersen and E. K. Horwitz, "Language Learning and Perfectionism: Anxious and NonAnxious Language Learners' Reactions to Their Own Oral Performance," Mod. Lang. J., vol. 86, no. 4, pp. 562-570, 2002.

[14] S. S. Liaw, "Investigating students' perceived satisfaction, behavioral intention, and effectiveness of e-learning: A case study of the Blackboard system," Comput. Educ., vol. 51, no. 2, pp. 864-873, 2008.

[15] R. S. Davies, D. L. Dean, and N. Ball, "Flipping the classroom and instructional technology integration in a college-level information systems spreadsheet course," Educ. Technol. Res. Dev., vol. 61, no. 4, pp. 563-580, 2013.

[16] F. Orooji and F. Taghiyareh, "Supporting participants in web-based collaborative learning activities from a holistic point of view: a tale of seven online and blended courses," J. Comput. Educ., vol. 2, no. 2, pp. 183-210, 2015. 